\title{
Pediatric imaging in the developing world: Colombia
}

\author{
Diego Jaramillo • Juana M. Vallejo • Kassa Darge
}

Received: 19 November 2013 / Accepted: 3 February 2014

(C) Springer-Verlag Berlin Heidelberg 2014

In 2012 out of a total Colombian population of $46,929,000$, $34 \%$ were children younger than 18 years and $10 \%$ were children younger than 5 years [1]. The number of radiologists in Colombia has been estimated at 1,245 [2]. There are less than ten pediatric radiologists practicing in Colombia but more than ten Colombian pediatric radiologists practicing in the United States and Canada. There are 15 radiology residency programs in Colombia and no pediatric radiology fellowships. There is clearly a need for greater outreach of pediatric imaging education to Colombia.

For many years, the Colombian Association of Radiology has coordinated pediatric radiology teaching in Colombia. Many pediatric radiologists lecture during its annual meeting, a radiology education forum for Central America and South America. The most recent congress, held in August 2013 in conjunction with the Latin American Society of Pediatric Radiology (SLARP), had a very strong pediatric presence. In the general meeting there were 1,322 participants from 14 countries, 192 academic sessions and 82 invited lecturers. Of these, there were 21 pediatric radiology lecturers from United States, Canada, Spain, Argentina, Panama, Venezuela, Brazil and Colombia and 11 academic sessions, all on behalf of SLARP (personal communication, Margarita María Tamayo, President, SLARP).

\footnotetext{
D. Jaramillo $(\varangle) \cdot K$. Darge

Department of Radiology, The Children's Hospital of Philadelphia,

Perelman School of Medicine, University of Pennsylvania,

34th Street and Civic Center Boulevard

Philadelphia, PA 19104, USA

e-mail: jaramillo@email.chop.edu

J. M. Vallejo

Department of Radiology, Javeriana University, Bogotá, Colombia
}

In March of 2013 the departments of radiology of the Children's Hospital of Philadelphia and the IATM (Institute of Medical Technology) of Medellín, Colombia, held a joint symposium of pediatric MRI and CT, with speakers from both institutions. The meeting had more than 280 participants and was the first of its kind.

In October of 2013, an educational meeting of the Zona Cafetera Division of the Colombian Association of Radiology was devoted in part to pediatric radiology, with participation of four pediatric radiologists from Colombia and the United States.

Increasingly, radiology residents from Colombia are coming to the United States and other countries for training in pediatric radiology. Most of this training is done informally as observerships, but recently it has become more formal; for instance, radiology residents from the Pontificia Universidad Javeriana in Bogotá are now training at the Children's Hospital of Philadelphia.

In summary, despite many valuable initiatives to increase pediatric radiology education in Colombia, there is a strong need for more educational and scientific outreach, given the size of the pediatric population in Colombia and the impact that improved pediatric imaging care could have on children's health.

Conflicts of interest None.

\section{References}

1. UNICEF. Available via http://www.UNICEF.org/spanish/ infobycountry/Colombiastatistics.html. Accessed 15 Oct 2013

2. Colombian Association of Radiologists. Available via http://www. Acronline.org/institucional/productosyservicios.aspx. Accessed 15 Oct 2013 